\title{
Trends in Downward Solar Radiation at the Surface over North America from Climate Model Projections and Implications for Solar Energy
}

\author{
Gerardo Andres Saenz and Huei-Ping Huang \\ School for Engineering of Matter, Transport and Energy, Arizona State University, Tempe, AZ 85281, USA \\ Correspondence should be addressed to Huei-Ping Huang; hp.huang@asu.edu
}

Received 1 May 2014; Accepted 6 August 2014

Academic Editor: Taewoo Lee

Copyright (C) 2015 G. A. Saenz and H.-P. Huang. This is an open access article distributed under the Creative Commons Attribution License, which permits unrestricted use, distribution, and reproduction in any medium, provided the original work is properly cited.

The projected changes in the downward solar radiation at the surface over North America for late 21st century are deduced from global climate model simulations with greenhouse-gas (GHG) forcing. A robust trend is found in winter over the United States, which exhibits a simple pattern of a decrease of sunlight over Northern USA. and an increase of sunlight over Southern USA. This structure was identified in both the seasonal mean and the mean climatology at different times of the day. It is broadly consistent with the known poleward shift of storm tracks in winter in climate model simulations with GHG forcing. The centennial trend of the downward shortwave radiation at the surface in Northern USA. is on the order of $10 \%$ of the climatological value for the January monthly mean, and slightly over $10 \%$ at the time when it is midday in the United States. This indicates a nonnegligible influence of the GHG forcing on solar energy in the long term. Nevertheless, when dividing the $10 \%$ by a century, in the near term, the impact of the GHG forcing is relatively minor such that the estimate of solar power potential using present-day climatology will remain useful in the coming decades.

\section{Introduction}

The last decade has witnessed a rapid development in solar energy as an alternative to fossil-fuel based energy. Solar power plants with increasing size and efficiency have been built. With an increased stake in the investment and return, site selection and assessments of long-term sustainability for solar power plants become increasingly important. One of the factors that affect the long-term planning for solar energy is the local climatology. Long hours of sunshine at a location are essential for a viable solar power plant. The available solar energy at a given site is quantified by the downward solar (shortwave) radiation at the surface. At a given latitude and day of the year, this quantity is affected by atmospheric water vapor and trace gases, the amount of aerosols in the atmosphere, and, most importantly, cloud cover (e.g., Li et al. [1]). Considering those factors, climatological maps of downward solar radiation have been widely produced for solar energy applications (e.g., National Renewable Energy Laboratory, http://www.nrel.gov/gis/solar.html, Maxwell et al. [2], and George and Maxwell [3]). Since climate is constantly changing due to anthropogenic and natural processes, the estimates of solar power potential based on present-day climatology are not guaranteed to be true in the future. In this study, we will analyze the projection of the changes in the downward solar radiation in the 21st century over North America using a set of climate model simulations driven by anthropogenic greenhouse-gas (GHG) forcing from the Climate Model Intercomparison Project-Phase 3 (CMIP3) archive (Meehl et al. [4]). The global climate models have relatively coarse horizontal resolutions but are capable of producing the first-order features of atmospheric general circulation. Over North America, GHG-induced changes in the large-scale circulation are known to produce future drying in the Southwest USA and a poleward shift of storm tracks over Western USA (e.g., Seager et al. [5] and Baker and Huang [6]). These changes potentially imply more sunshine in the Southwest USA but reduced sunshine in the higher latitudes in Western USA due to increased cloudiness associated with storms. We will quantify the extent to which these changes in 
atmospheric processes affect the downward solar radiation at the surface, as directly calculated by the climate models using their physical parameterization schemes.

For solar energy applications, it is relevant to know not only the changes in the seasonal mean solar radiation but also how these changes are distributed through different times of the day. The analysis of the latter requires subdaily data of solar radiation, which were archived only by a small number of modeling groups in CMIP. Nevertheless, with the limited data, we will make a first attempt to quantify the trends at different times of the day.

\section{Data from Climate Model Simulations}

We will analyze two sets of climate model simulations from the CMIP3 archive (http://www-pcmdi.llnl.gov/ipcc/ about_ipcc.php). Although a large collection of model outputs have been archived by CMIP3 and the more recent CMIP5 (Taylor et al. [7]), the majority of the data are monthly means. Subdaily outputs are archived by only a small number of modeling groups and for short time periods. In this study, we choose to analyze the GFDL CM2.0 and MRI CGCM2.3.2 simulations in CMIP3. Both groups provided subdaily (3hourly) archives of downward shortwave radiation at the surface for selected time slices in late 20th century and late 21st century. The surface radiation budget for CMIP3 20th century simulations was analyzed and compared to observation by Wild [8]. Over the midlatitude belt from $30 \mathrm{~N}$ to $60 \mathrm{~N}$, the MRI model has about $+15 \mathrm{~W} / \mathrm{m}^{2}$ bias while the GFDL model has about $-5 \mathrm{~W} / \mathrm{m}^{2}$ bias in the all-sky downward shortwave radiation at the surface (see Figure 6 in Wild $[8])$.

For both models, the GHG-induced trend will be deduced from the difference between the SRES A1B run (with increasing GHG concentration according to the A1B scenario) for the 21 st century and the $20 \mathrm{C} 3 \mathrm{M}$ run for the 20th century. We will first use the monthly mean archives to calculate the centennial trend, defined as the climatology of 2080-2100 minus the climatology of 1980-2000. For the analysis of the trends at different times of the day, we will use the 3-hourly model outputs as available from CMIP3. Each modeling group only provided the high-frequency data for short time slices in the late 20th century and late 21st century. Based on the availability of data, we will use the difference between year 2100 (from SRES A1B runs) and year 2000 (from 20C3M runs) to calculate the trends at selected local times during the day in North America.

This study will focus on the climate trend over North America. Over the Eurasian continent, Meleshko et al. [9] have shown that CMIP3 models project a $2-4 \%$ increase in winter and $2-10 \%$ decrease in summer of cloud cover (total cloud fraction) over Russia. The latter corresponds to an increase of $4-5 \mathrm{~W} / \mathrm{m}^{2}$ in summer in the area-averaged downward shortwave radiation at the surface. Since the populous regions in North America are located at lower latitudes than Russia, a similar change in cloud cover over North America is expected to produce a greater change in the downward shortwave radiation at the surface.

\section{Results and Discussion}

3.1. Monthly Mean Climatology and Trend. Figures 1(a) and 1(b) show the July climatology of the downward shortwave radiation at the surface over North America from GFDL CM2.0 simulations. Figure 1(a) is the 2080-2100 average from the SRES A1B run and Figure 1(b) is the 1980-2000 average from the $20 \mathrm{C} 3 \mathrm{M}$ run. Figure 1(c) shows the trend deduced from the difference (future minus present) between Figures 1(a) and 1(b). For the climatology in Figures 1(a) and 1(b), although the downward solar radiation is zonally uniform at the top of the atmosphere, it becomes significantly nonuniform upon reaching the surface. This longitudinal nonuniformity is strongly influenced by cloudiness, as can be readily seen in Figure 2, the counterpart of Figure 1 for the total cloud fraction in July from the same simulations. For example, the strong downward shortwave radiation at the surface over Western and Southwest USA corresponds to the mostly clear-sky condition in July in those regions. In Figure 1(c), the model projected an overall positive trend over most of the United States, except for a small area in the Southwest USA. The increased sunlight at the surface, on the order of about $20 \mathrm{~W} / \mathrm{m}^{2}$ (over the 21st century) or close to $10 \%$ of the climatology, is related to a reduced cloudiness over the USA (Figure 2(c)).

Figure 3 is similar to Figure 1 but for January. The trend in winter (Figure 3(c)) is an increase of the downward shortwave radiation over Southern and Southwest USA and a decrease of it over the northern half of the USA. The increased sunlight over Southwest USA in the cold season is consistent with the known projection by climate models of a drying trend in that region (Seager et al. [5] and Baker and Huang [6]). This drying trend is related, in part, to the poleward shift of storm tracks (Seager et al. [5]), which is consistent with the decrease in sunlight over Northern USA since the increase in storm activities implies an increase in cloudiness.

The downward shortwave radiation at the surface simulated by MRI CGCM2.3.2 is shown in Figure 4. For conciseness, only the trends are shown. Figures 4(a) and 4(b), for July and January, respectively, are the counterparts of trends in Figures 1(c) and 3(c). In summer, the trend simulated by the MRI model is significantly different from that produced by the GFDL model. While both models project an increase of sunlight over Eastern USA and the Pacific Northwest, MRI projects a neutral to slightly negative trend over Western USA compared to a positive trend by the GFDL model. The trend in winter is more robust. Both models produced a decrease of sunlight over Northern USA and an increase of it over Southern USA. For both models, the magnitude of these trends is on the order of $10 \mathrm{~W} / \mathrm{m}^{2}$, or about $10 \%$ of the January climatology. As a notable difference, over the Southwest USA, GFDL CM2.0 produced a positive trend while MRI CGCM2.3.2 produced a neutral to negative trend. Since the trend in the shortwave radiation is strongly influenced by the trend in cloudiness which is highly parameterized in climate models, the differing projections by the two models are not surprising. A better agreement in the trend is found in January, possibly because the decrease in sunlight over Northern USA in the cold season is related to the poleward 


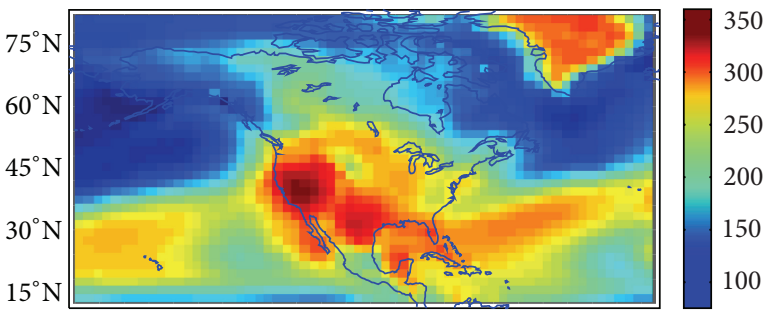

(a)

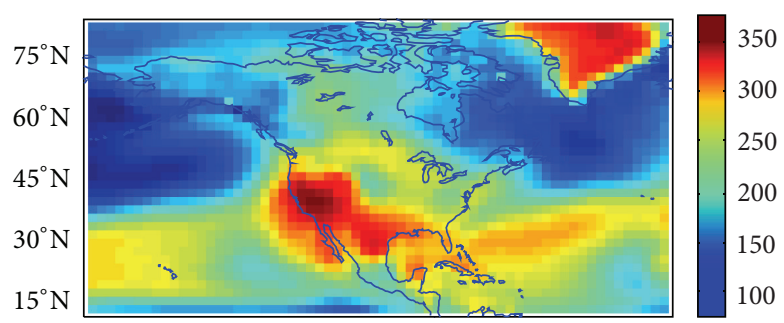

(b)

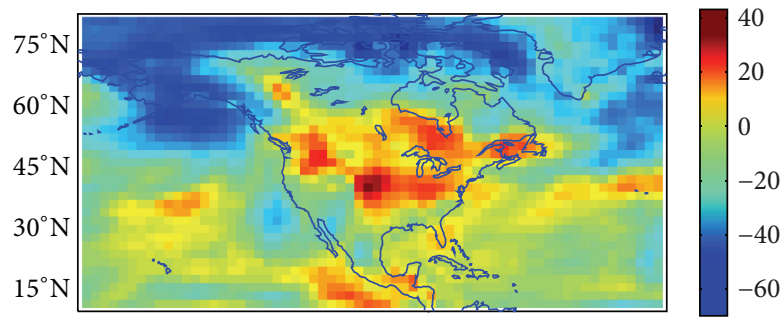

(c)

FIGURE 1: (a) The July climatology of downward shortwave radiation at the surface over North America from the 21st century run with GFDL CM2.0, based on 2080-2100 average. (b) The same as (a) but from the 20th century run, based on 1980-2000 average. (c) The trend, defined as (a) minus (b). The color scales with units in $\mathrm{W} / \mathrm{m}^{2}$ are shown on the right.

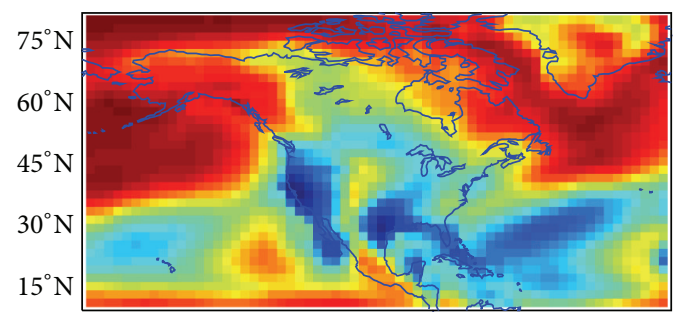

(a)

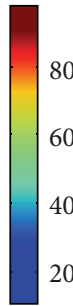

$15^{\circ} \mathrm{N}$

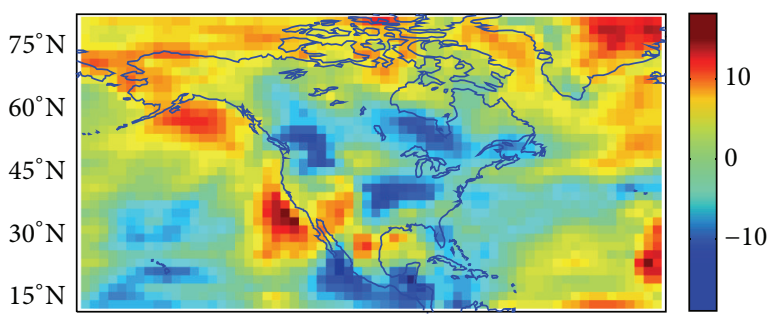

(c)

FIGURE 2: (a) The July climatology of total cloud fraction from the 21st century run with GFDL CM2.0, based on 2080-2100 average. (b) The same as (a) but from the 20th century run, based on 1980-2000 average. (c) The trend, defined as (a) minus (b). The color scales with units in percentage are shown on the right.

shift of storm tracks under an increasing GHG forcing, a phenomenon that is large scale in nature and is robustly simulated by the majority of climate models in CMIP3 (e.g., Yin [10]).

3.2. Trends at Different Times of the Day. We next use the more limited data of 3-hourly model outputs to deduce the trends in the downward shortwave radiation at the surface as a function of the times of the day. Both GFDL CM2.0 and MRI CGCM2.3.2 provide the 3-hourly archives for the downward shortwave radiation for the year 2000 (from the
$20 \mathrm{C} 3 \mathrm{M}$ runs) and 2100 (from the SRES A1B runs). Figure 5 illustrates a 3-hourly time series of the downward shortwave radiation at the surface averaged over multiple grid points in Northern Arizona, for the year 2000, from the 20C3M simulation with GFDL CM2.0. The trend (now defined as the 2100 average minus the 2000 average) discussed in this section will be for a specific time of the day, averaged over either July or January.

Figures 6(a)-6(c) are similar to Figures 1(a)-1(c) but for the GFDL CM2.0 simulations of the shortwave radiation at 3 PM local time of US West Coast. Figure 6(a) is the average 


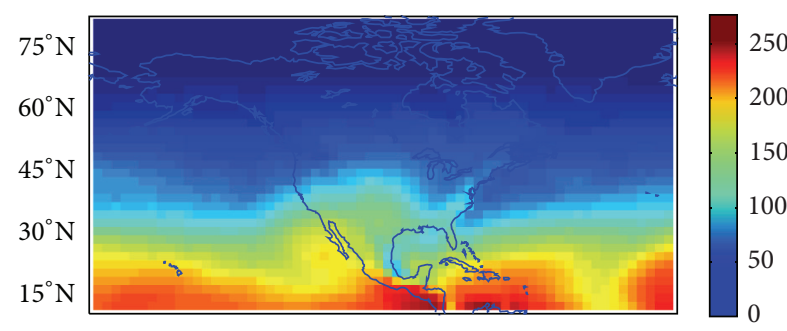

(a)

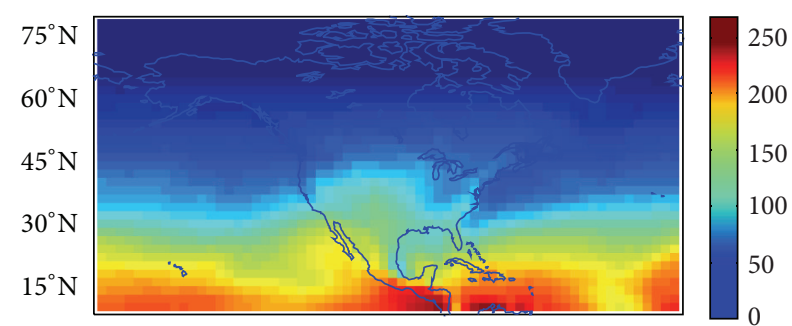

(b)

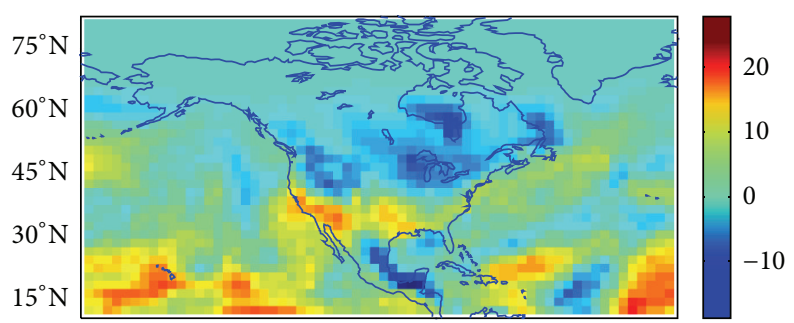

(c)

Figure 3: (a) The January climatology of downward shortwave radiation at the surface from the 21st century run with GFDL CM2.0, based on 2080-2100 average. (b) The same as (a) but from the 20th century run, based on 1980-2000 average. (c) The trend, defined as (a) minus (b). The color scales with units in $\mathrm{W} / \mathrm{m}^{2}$ are shown on the right.

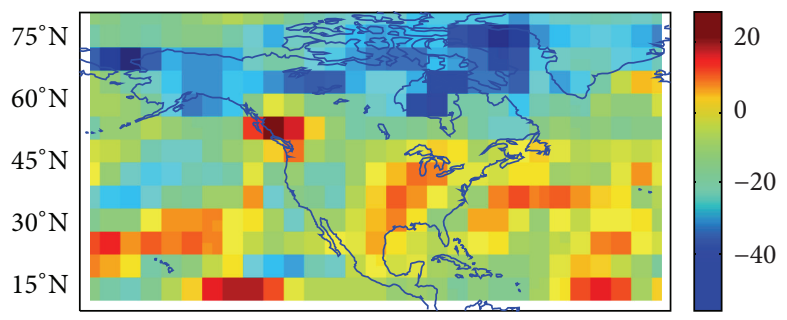

(a)

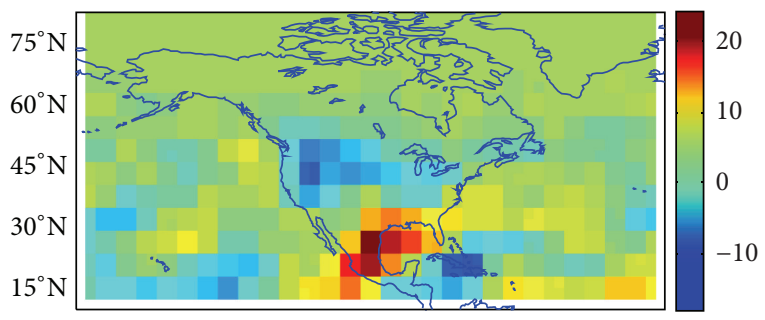

(b)

FIgURE 4: (a) The trend of the downward shortwave radiation at the surface for July from the MRI CGCM2.3.2a simulations. (b) The same as (a) but for January. The trend is defined as the 2080-2100 mean climatology minus the 1980-2000 climatology. Color scales with units of $\mathrm{W} / \mathrm{m}^{2}$ are shown on the right.

over July 2100 and Figure 6(b) the average over July 2000. The trend, defined by 2100 minus 2000, is shown in Figure 6(c). Figures 6(d)-6(f) are the counterparts of Figures 6(a)-6(c) but for the MRI CGCM2.3.2 simulations. Figure 7 is similar to Figure 6 but for the shortwave radiation at 9 a.m. local time of US West Coast. Note that the climatological values and trends in Figures 6 and 7 are much higher than the monthly mean values in Figure 1 because the latter are the average over the whole day, including nighttime. Just like the monthly mean, in July, the trends projected by the two models are significantly different. Also, within each model, the trend at a particular time of the day is different from the trend of the monthly mean which includes the contributions from all times of the day.

While the trends in July are not robust, the trends in January as shown in Figure 8 exhibit a greater degree of consistency between the two models and across different times of the day. For conciseness, only the trends are shown. Figures $8(\mathrm{a})$ and $8(\mathrm{~b})$ are the January trend at 3 p.m., and

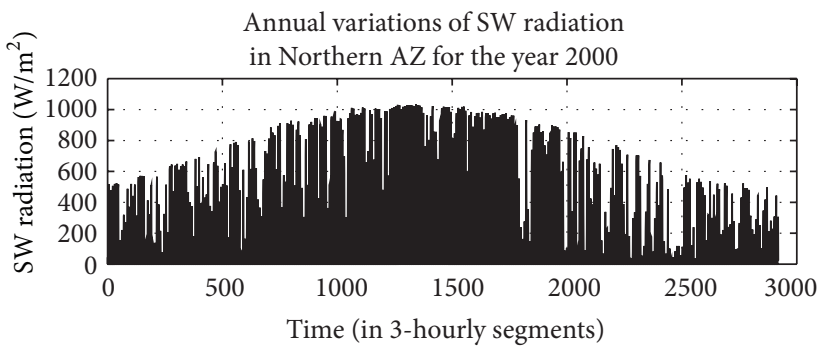

FIGURE 5: The time series of three-hourly downward shortwave radiation at surface, averaged over multiple grid points that cover Northern Arizona, for the year 2000 from the GFDL CM2.0 20th century simulation. The unit on the ordinate is $\mathrm{W} / \mathrm{m}^{2}$.

Figures $8(\mathrm{c})$ and $8(\mathrm{~d})$ are the January trend at 9 a.m. local time of US West Coast. The top row (Figures $8(\mathrm{a})$ and $8(\mathrm{c})$ ) is from GFDL CM2.0 and bottom row (Figures $8(\mathrm{~b})$ and $8(\mathrm{~d})$ ) 


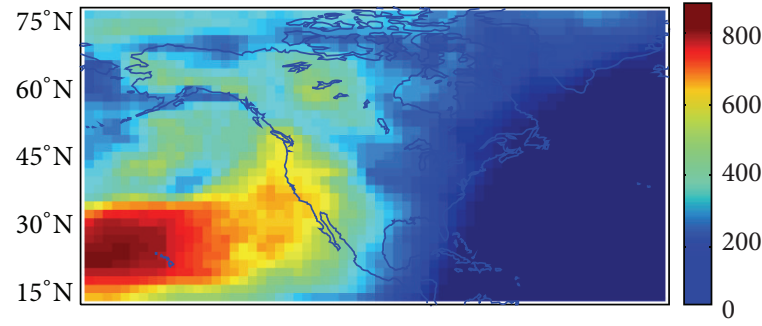

(a)

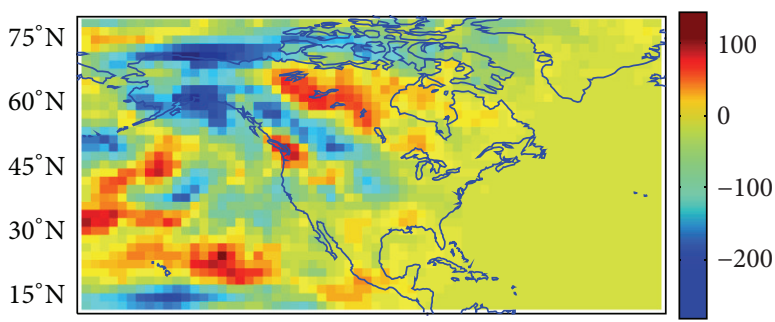

(c)

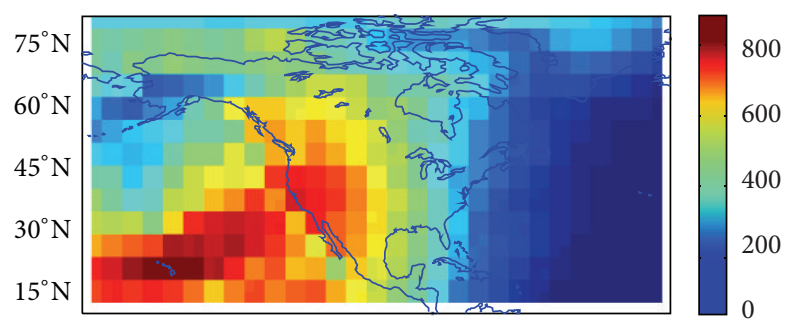

(e)

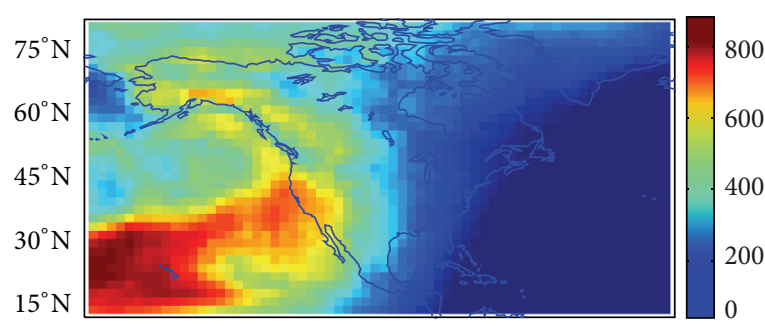

(b)

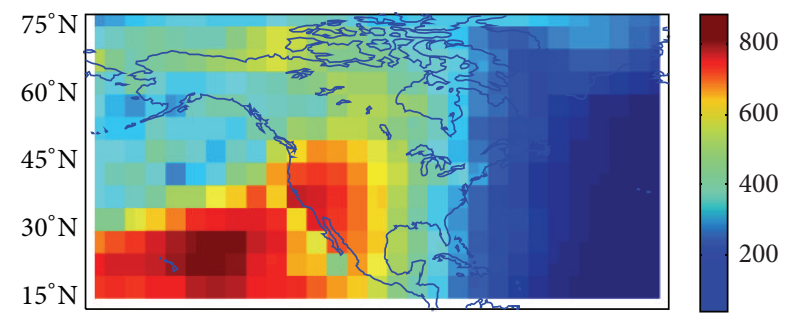

(d)

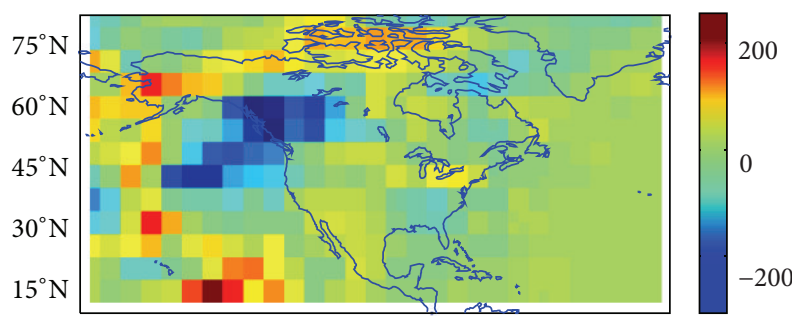

(f)

FIGURE 6: (a) The downward shortwave radiation at the surface at 3 PM local time of US West Coast, averaged over July 2100, from the GFDL CM2.0 21st century run. (b) The same as (a) but for the average over July 2000 from the GFDL CM2.0 20th century run. (c) The trend, defined as (a) minus (b). Panels (d)-(f) are the counterparts of (a)-(c) from the MRI CGCM2.3.2 simulations. The color scale with units of W/m ${ }^{2}$ is shown on the right for each panel.

from MRI CGCM2.3.2 simulations. The decrease in sunlight at the surface over Northern USA and the increase of it over Southern USA, as previously shown in the monthly mean plots in Figures 3 and 4, can be identified in all four panels in Figure 8. From Figures 8(c) and 8(d), at the time when the entire United States is in the middle of the day, the January trend of the decrease in solar radiation in Northern USA can locally reach $100 \mathrm{~W} / \mathrm{m}^{2}$, or slightly over $10 \%$ of the local climatological value at that time.

\section{Concluding Remarks}

The most robust finding of this study is the wintertime (January) trend in the downward shortwave radiation at the surface over the United States. It exhibits a simple pattern of a decrease of sunlight over Northern USA and an increase of sunlight over Southern USA. This structure is simulated by both GFDL and MRI models and can be identified even at different times of the day. It is broadly consistent with the known poleward shift of storm tracks in the cold season in climate model simulations under an increasing GHG forcing. The negative trend in Northern USA is more prominent. Quantitatively, the centennial trend of the downward shortwave radiation at the surface in that region is on the order of $10 \%$ of the climatological value for the monthly mean (averaged over all times of the day) and slightly over $10 \%$ at the time when it is midday in the United States. This indicates a nonnegligible influence of the GHG forcing on solar energy in the long term. Nevertheless, when dividing the $10 \%$ by a century, in the near term, the impact of the GHG forcing is relatively minor such that the estimate of solar power potential using present-day climatology will remain useful in the coming decades. The global climate models used in this study have relatively coarse resolutions with the horizontal grid size exceeding $100 \mathrm{~km}$. For the assessment of solar power potential at a specific site of existing or future solar power plant, it will be desirable to perform climate downscaling (e.g., Mearns et al. [11] and Sharma and Huang [12]) to take into account the effects of small-scale topography on cloudiness. The findings of this work will serve as a useful reference for future studies in that direction. 


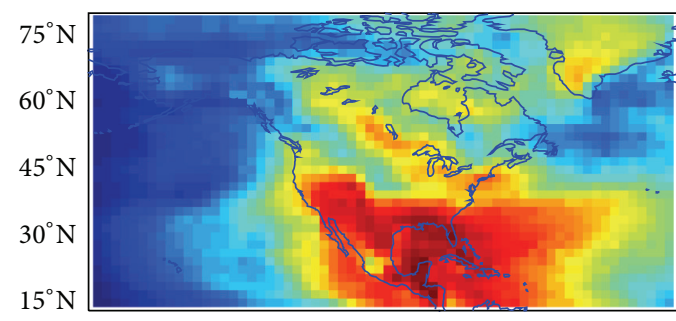

(a)

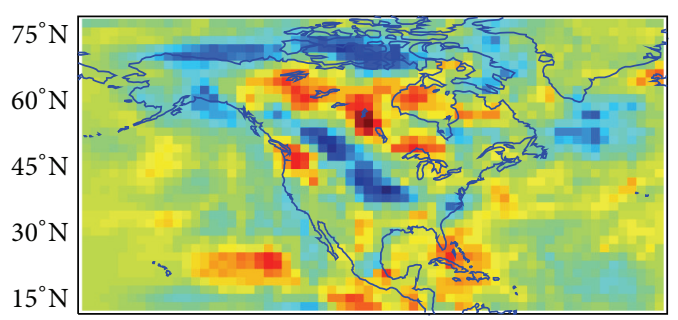

(c)

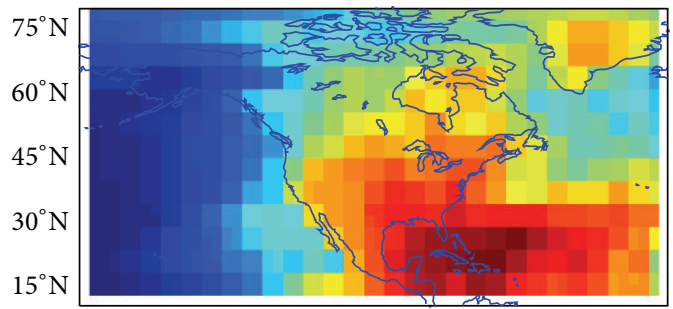

(e)

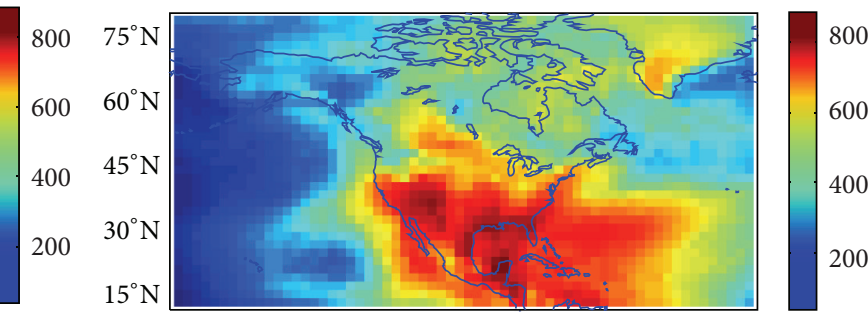

(b)

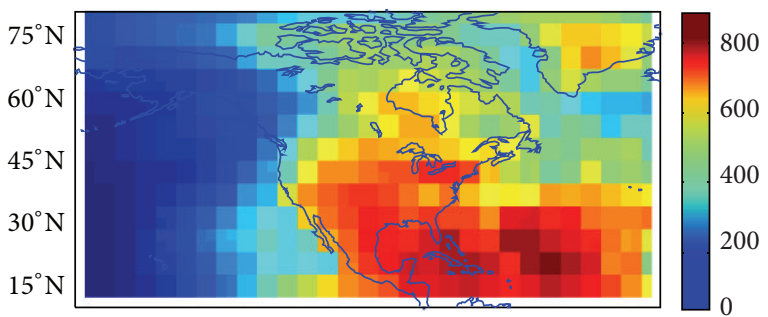

(d)

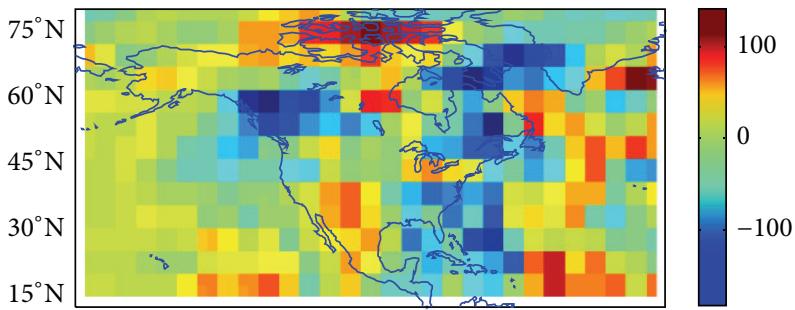

(f)

Figure 7: The same with Figure 6 but for the downward shortwave radiation at 9AM local time of US West Coast for July. Panels (a)-(c) are from GFDL CM2.0 and panels (d)-(f) are from MRI CGCM2.3.2 simulations. The color scale with units of W/m² is shown on the right for each panel.

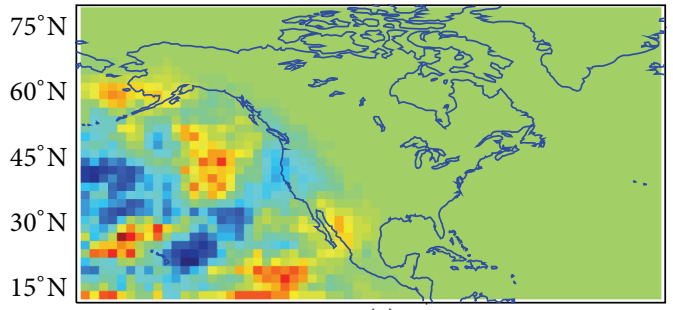

(a)

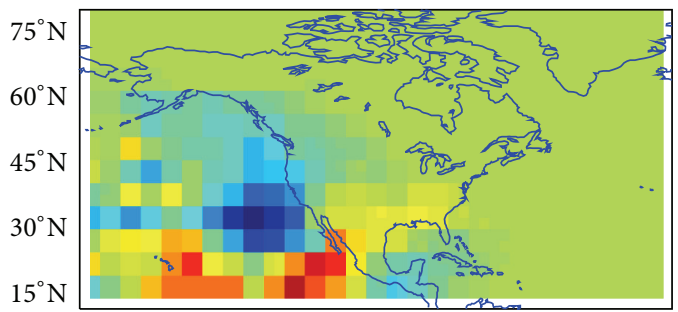

(b)
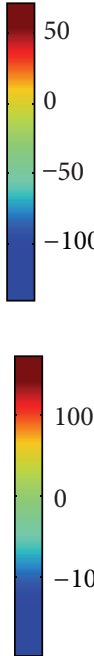

$75^{\circ} \mathrm{N}$
$60^{\circ} \mathrm{N}$
$45^{\circ} \mathrm{N}$
$-100^{\circ} \mathrm{N}$
$15^{\circ} \mathrm{N}$

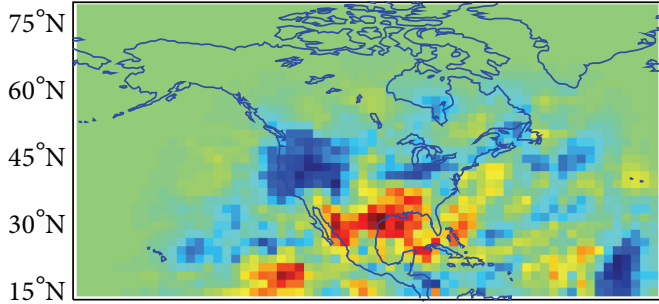

(c)

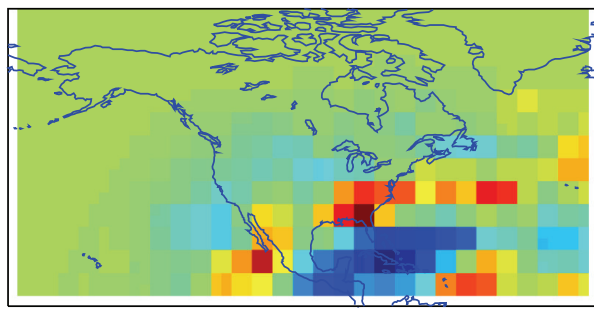

(d)

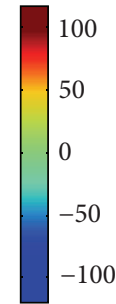

$-100$

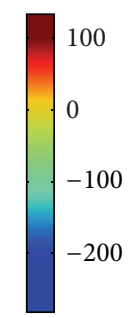

FIGURE 8: (a) The trend of downward shortwave radiation at surface at 3 p.m. local time of US West Coast, defined in the same manner as Figure 6(c) but for the average over January, from GFDL CM2.0 simulations. (b) The same as (a) but from MRI CGCM2.3.2 simulations. Panels (c) and (d) are the counterparts of (a) and (b) but for 9 a.m. local time of US West Coast, also averaged over January. The trends in all four panels are defined as January 2100 average minus January 2000 average. The color scale with units of W/ $\mathrm{m}^{2}$ is shown on the right for each panel. 


\section{Conflict of Interests}

The authors declare that there is no conflict of interests regarding the publication of this paper.

\section{References}

[1] Z. Li, H. W. Barker, and L. Moreau, "The variable effect of clouds on atmospheric absorption of solar radiation," Nature, vol. 376, no. 6540, pp. 486-490, 1995.

[2] E. Maxwell, R. George, and S. Wilcox, "A climatological solar radiation model," in Proceedings of the Annual Conference, American Solar Energy Society, p. 6, Albuquerque, NM, USA, 1998.

[3] R. George and E. Maxwell, "High-resolution maps of solar collector performance using a climatological solar radiation model," in Proceedings of the 1999 Annual Conference, p. 6, American Solar Energy Society, Portland, Me, USA, 1999.

[4] G. A. Meehl, C. Covey, K. E. Taylor et al., "The WCRP CMIP3 multimodel dataset: A new era in climatic change research," Bulletin of the American Meteorological Society, vol. 88, no. 9, pp. 1383-1394, 2007.

[5] R. Seager, M. Ting, I. Held et al., "Model projections of an imminent transition to a more arid climate in southwestern North America," Science, vol. 316, no. 5828, pp. 1181-1184, 2007.

[6] N. C. Baker and H.-P. Huang, "A comparative study of precipitation and evaporation in semi-arid regions between the CMIP3 and CMIP5 climate model ensembles," Journal of Climate, vol. 27, pp. 3731-3749, 2014.

[7] K. E. Taylor, R. J. Stouffer, and G. A. Meehl, "An overview of CMIP5 and the experiment design," Bulletin of the American Meteorological Society, vol. 93, no. 4, pp. 485-498, 2012.

[8] M. Wild, "Short-wave and long-wave surface radiation budgets in GCMs: a review based on the IPCC-AR4/CMIP3 models," Tellus A, vol. 60, no. 5, pp. 932-945, 2008.

[9] V. P. Meleshko, V. M. Kattsov, V. A. Govorkova, P. V. Sporyshev, I. M. Shkol'nik, and B. E. Shneerov, "Climate of Russia in the 21st century. Part 3. Future climate changes calculated with an ensemble of coupled atmosphere-ocean general circulation CMIP3 models," Russian Meteorology and Hydrology, vol. 33, no. 9, pp. 541-552, 2008.

[10] J. H. Yin, "A consistent poleward shift of the storm tracks in simulations of 21st century climate," Geophysical Research Letters, vol. 32, no. 18, Article ID L18701, pp. 1-4, 2005.

[11] L. O. Mearns, R. Arritt, S. Biner et al., "The north american regional climate change assessment program: overview of phase I results," Bulletin of the American Meteorological Society, vol. 93, no. 9, pp. 1337-1362, 2012.

[12] A. Sharma and H.-P. Huang, "Regional climate simulation for Arizona: impact of resolution on precipitation," Advances in Meteorology, vol. 2012, Article ID 505726, 13 pages, 2012. 

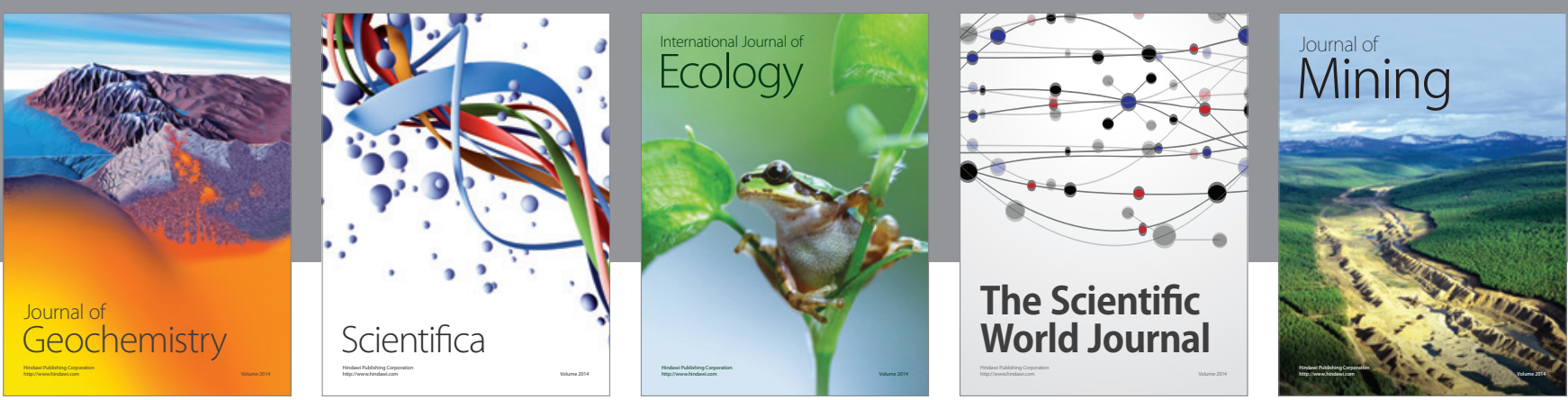

The Scientific World Journal
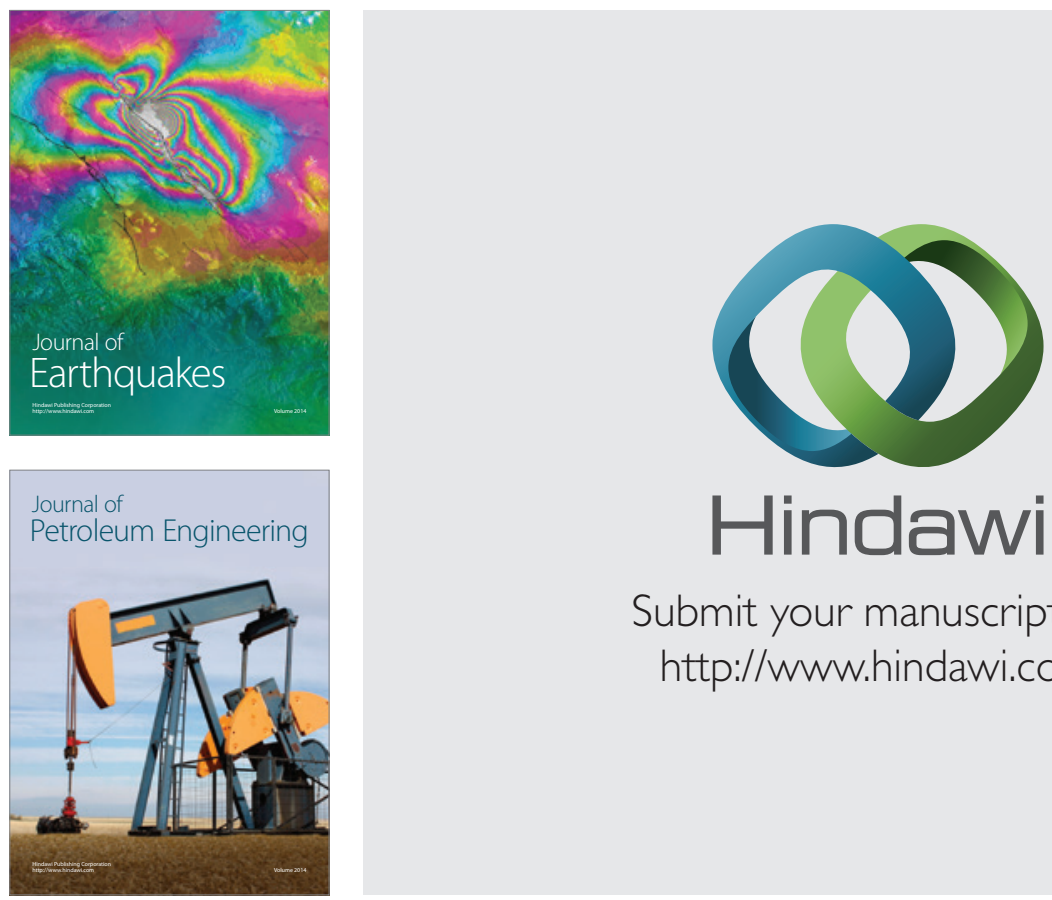

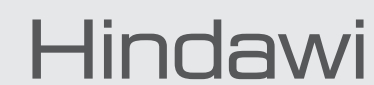

Submit your manuscripts at

http://www.hindawi.com
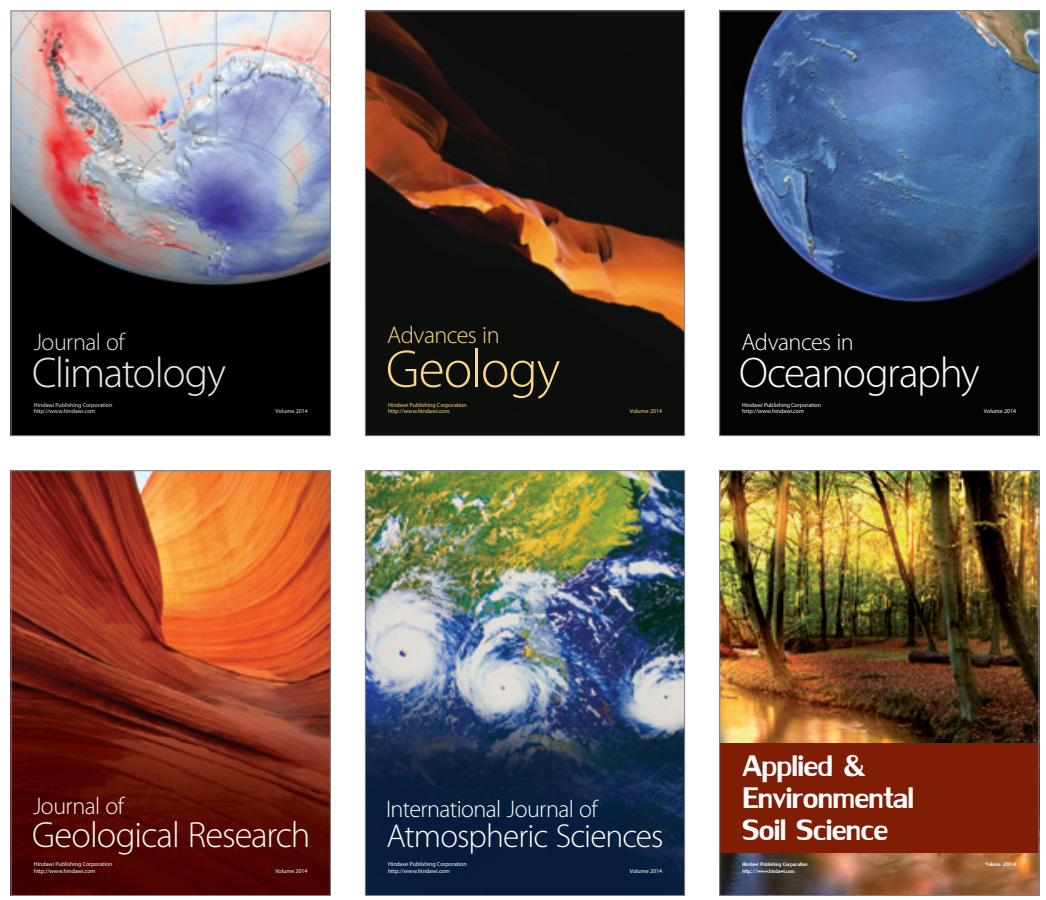
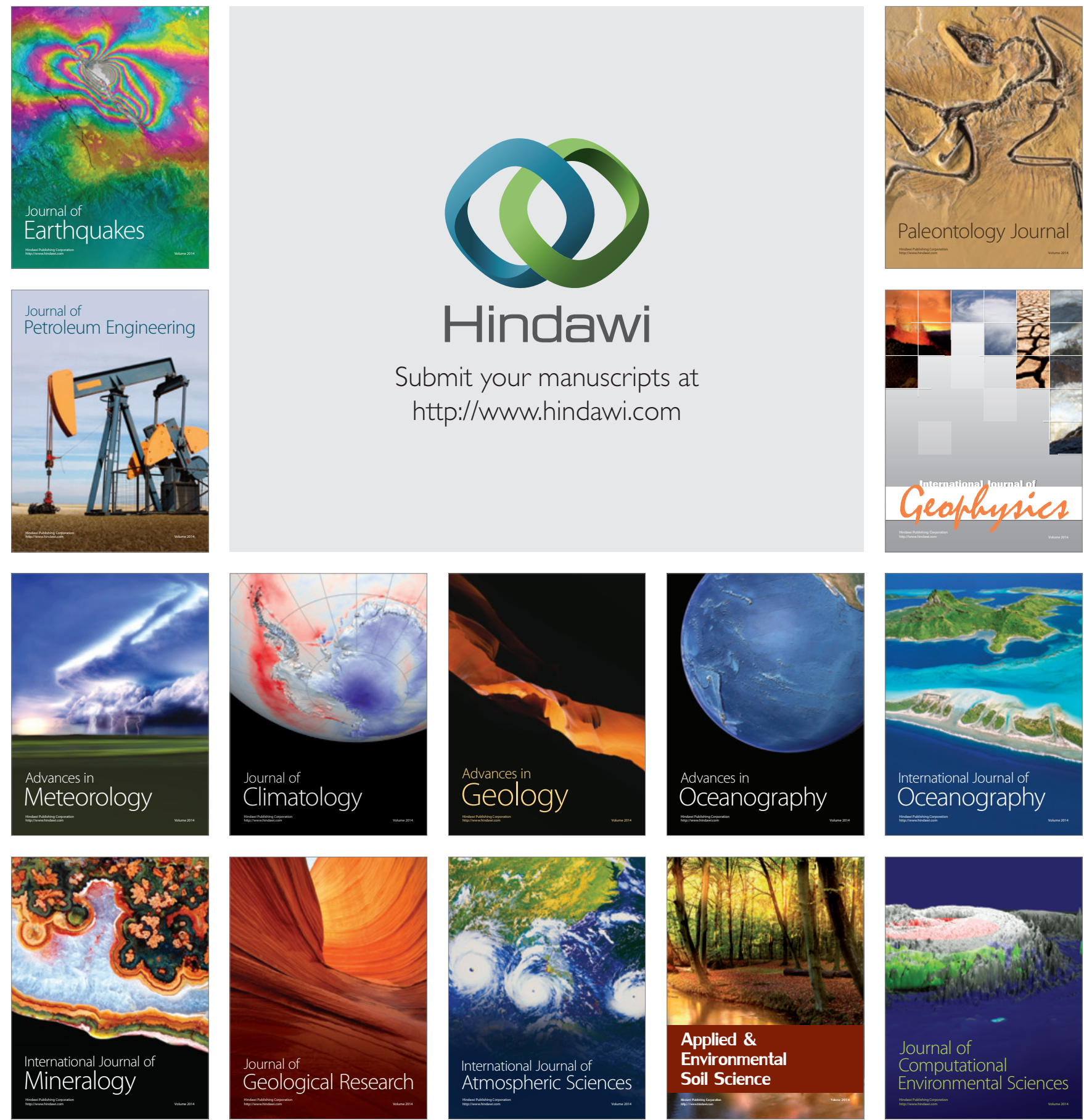